INSERM U-434, CEPH, 27 rue Juliette Dodu, F-75010, Paris, France

S Olschwang

G Thomas

Molecular Genetics, Pathology

Department, Dunedin

School of Medicine, Dunedin, New Zealand

D Markie

Section of Molecular Carcinogenesis, Institute of Cancer Research, Sutton,

Surrey, UK

S Seal

M Stratton

I Tomlinson

Polyposis Registry, St Mark's Hospital, Watford Road, Harrow, UK

K Neale

R Phillips

Cancer Genetics Laboratory, Imperial Cancer Research

Fund, 44 Lincoln's Inn

Fields, London, UK

$S$ Cottrell

W Bodmer

Department of Clinical Genetics, Alder Hey Children's Hospital, Liverpool, UK

I Ellis

Department of Clinical Genetics, Guy's Hospital, London, UK $S$ Hodgson

Old Hills Road, Livingston, New Jersey, USA

P Zauber

Academic Department of Surgery, St Mary's

Hospital, London, UK A Spigelman

Centre for Polyposis and Intestinal

Diseases, 1-5-45, Yushima, Bunkyo-Ku, Tokyo 113, Japan

T Iwama

Kinderchirurg Klinik, University of

Heidelberg, Theodor

Kutzer Ufer,

Mannheim, Germany

S Loff

Clinical Genetics Unit Birmingham Women's Hospital,

Birmingham, UK

C McKeown

\title{
Peutz-Jeghers disease: most, but not all, families are compatible with linkage to $19 \mathrm{p} 13.3$
}

Sylviane Olschwang, David Markie, Sheila Seal, Kay Neale, Robin Phillips, Sally Cottrell, Ian Ellis, Shirley Hodgson, Peter Zauber, Allan Spigelman, Takeo Iwama, Steffan Loff, Carole McKeown, Cristiana Marchese, Julian Sampson, Sally Davies, Ian Talbot, John Wyke, Gilles Thomas, Walter Bodmer, Akseli Hemminki, Egle Avizienyte, Albert de la Chapelle, Lauri Aaltonen, Michael Stratton, Richard Houlston, Ian Tomlinson

\begin{abstract}
A locus for Peutz-Jeghers syndrome (PJS) was recently mapped to chromosome 19p13.3. Each of 12 families studied was compatible with linkage to the marker D19S886. We have analysed 20 further families and found that the majority of these are consistent with a PJS gene on 19p13.3. Three families were, however, unlinked to 19p13.3 and none of the available PJS polyps from these families showed allele loss at D19S886. There were no obvious clinicopathological or ethnic differences between the 19p13.3 linked and unlinked families. There appears, therefore, to be a major PJS locus on chromosome 19p13.3 and the possibility exists of a minor locus (or loci) elsewhere.

(F Med Genet 1998;35:42-44)
\end{abstract}

Keywords: Peutz-Jeghers disease; linkage; 19p13.3

Peutz-Jeghers syndrome (PJS) is a dominantly inherited disease of hamartomatous gastrointestinal polyps and mucocutaneous pigmentation of the lips, buccal mucosa, axillae, fingers, and toes. ${ }^{1}$ PJS predisposes to cancers of several sites (gastrointestinal tract, ovary, testis, endometrium, and breast). The PJS locus may therefore have a role in many sporadic cancers, as has the PTEN gene which is implicated in Cowden's disease and mutated in sporadic prostate and breast cancers and in some brain tumours. ${ }^{23}$

A PJS locus has recently been mapped to chromosome $19 \mathrm{p} 13.3 .^{4} \mathrm{~A}$ candidate site for a PJS gene was initially discovered using comparative genomic hybridisation (CGH) in PJS polyps. CGH detected deletions in polyps from a single PJS patient towards the telomere of chromosome $19 \mathrm{p}$, suggesting that the PJS gene acted as a tumour suppressor. After microdissection of the polyps, this region was confirmed as a site of allele loss using microsatellite markers and the allele derived from the unaffected parent was consistently lost. Twelve families were then studied by linkage analysis, producing a combined two point lod score at D19S886 (the most telomeric marker on the Genethon genetic map) of $5.40(\theta=0)$ and a multipoint lod score of 7.00 .

There was no evidence of genetic heterogeneity in the 12 families originally studied by linkage analysis, although they were of several different ethnic origins and had varying severities of disease (as regards age of presentation, development of complications, and tendency to develop cancer). Nevertheless, the possible existence of genetic heterogeneity in PJS is important both for predictive genetic testing in families using markers close to the PIS locus and for efforts to identify the PJS gene which rely on critical recombinants. Thus, to test for genetic heterogeneity and to confirm $19 \mathrm{p} 13.3$ as the site of a PJS locus, we have ascertained a further 20 pedigrees with a diagnosis of PJS from clinicians in France (13 families), UK (three families), Germany (two families), Canada (one family), and Japan (one family). These families have been tested for linkage of PJS to D19S886 and to nearby markers (D19S886-5 cM-D19S878-1 cM-D19S565).

\section{Methods}

PJS families were ascertained through clinicians in their country of origin. Subjects were defined as affected by the presence of characteristic mucocutaneous pigmentation or hamartomatous gastrointestinal polyps or both. Other potentially useful clinical data, such as age of presentation, a family or personal history of cancers, and ethnic origin, were also obtained. Samples of peripheral blood $(10 \mathrm{ml})$ were taken from subjects useful for linkage analysis and DNA was extracted using standard methods. These subjects were genotyped at the D19S886, D19S878, and D19S565 microsatellite loci which map close to the telomere of chromosome $19 \mathrm{p}$. A total of $50 \mathrm{ng}$ of genomic DNA was amplified using the PCR in $25 \mu \mathrm{l}$ of $75 \mathrm{mmol} / 1$ Tris- $\mathrm{HCl}(\mathrm{pH} \mathrm{9)}$ $0.01 \%$ (v/v) Tween, $1.5 \mathrm{mmol} / 1 \mathrm{MgCl}_{2}, 0.25 \mathrm{U}$ Taq polymerase, $20 \mathrm{mmol} / 1\left(\mathrm{NH}_{4}\right)_{2} \mathrm{SO}_{4}, 0.1 \%$ (w/v) BSA, $0.2 \mathrm{mmol} / 1$ each $\mathrm{dNTP}$ and each primer at $5 \mathrm{ng} / \mu \mathrm{l}$. One primer had previously been end labelled with $\gamma^{32}$ ATP using $3 \mathrm{U}$ of T4 polynucleotide kinase. Thirty-five cycles of the PCR were carried out at $94^{\circ} \mathrm{C}$ for one minute, $55^{\circ} \mathrm{C}$ for one minute, and $72^{\circ} \mathrm{C}$ for one minute with a final extension step at $72^{\circ} \mathrm{C}$ for $10 \mathrm{~min}$ utes. The products were electrophoresed through $6 \%$ denaturing polyacrylamide gels, dried, and exposed to $x$ ray film for 24 hours.

Linkage analysis was performed using the MLINK program. PJS was modelled as a rare dominant trait $(q=0.0001)$ with high penetrance $(80 \%)$ and no phenocopies. Marker allele frequencies were estimated from pedigree founders. The order of and distances between the markers were based on the current Genethon map. Genetic heterogeneity was tested using the HOMOG program. 
Table 1 (A) Overall lod scores in the 20 families studied at the markers and recombination fraction $(\theta)$ shown. (B) Lod scores at D19S886 and D19S878 shown by family (No $7=$ family G199, No $13=$ family G69, No $17=$ family G842) for $\theta=0.01$

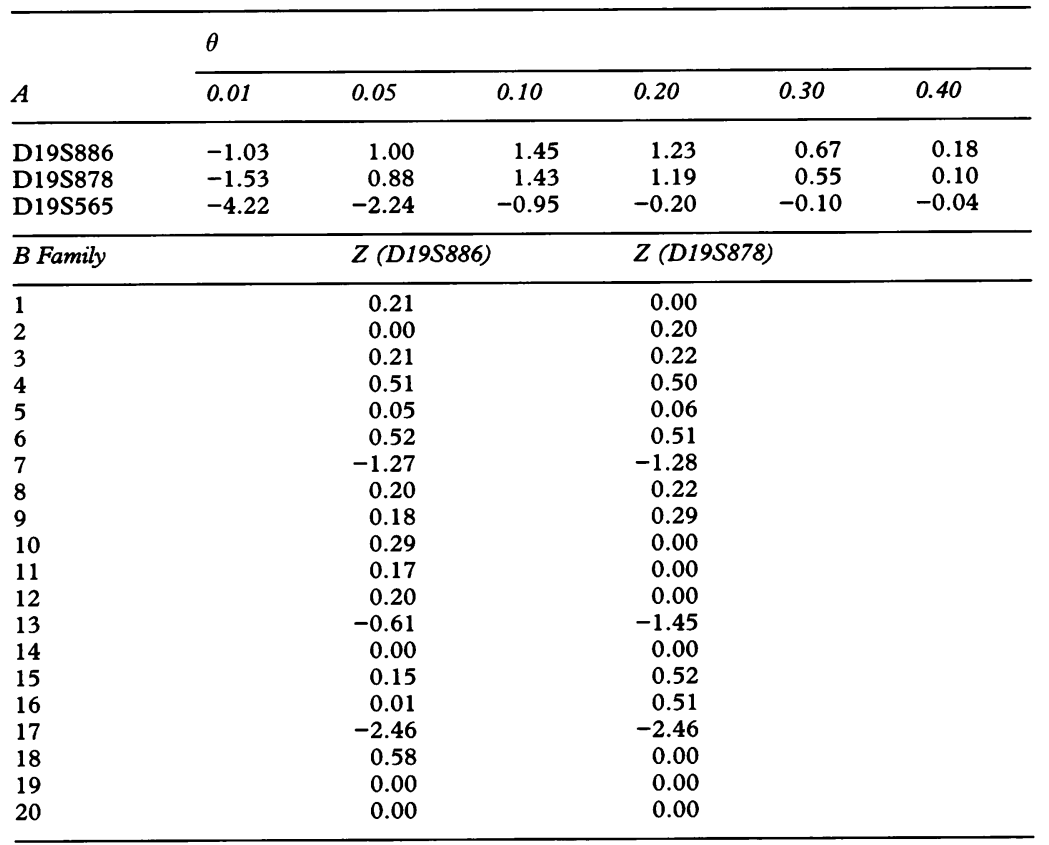

Ospedale Mauriziano "Umberto I" di Torino, Torino, Italy C Marchese

Department of Clinical Genetics, University Hospital of Wales, Heath Park, Cardiff, UK

J Sampson

S Davies

Academic Department of Pathology, St Mark's Hospital, Watford Road, Harrow, UK I Talbot

Department of Gastroenterology, Ipswich Hospital, Ispwich, UK J Wyke

Department of Medical Genetics, University of Helsinki, Finland

A Hemminki

E Avizienyte

A de la Chapelle

L Aaltonen

Department of Epidemiology, Research, Sutton,

Surrey, UK

R Houlston

I Tomlinson

Nuffield Department of Clinical Medicine, John Radcliffe Hospital, Oxford, UK I Tomlinson

Correspondence to: Dr Tomlinson.

Received 19 June 1997 Accepted for publication 4 August 1997
Sections of $20 \mu \mathrm{m}$ were cut from selected paraffin embedded PJS polyps, stained lightly with toluidine blue, and mounted on a glass slide. One $5 \mu \mathrm{m} \mathrm{H \& E}$ section was cut from the same block to provide an indication of tissue architecture and the extent of the epithelial tissue. The epithelial tissue was cut from each 20 $\mu \mathrm{m}$ section using a fine scalpel blade or a fine gauge needle under the dissecting microscope. DNA was extracted from the microdissected tissue by proteinase $\mathrm{K}$ digestion for three to five days and boiling for eight minutes. DNA from polyps and corresponding constitutional DNA were amplified in the PCR as above, except that fluorescent labelled oligonucleotides and the ABI semiautomated sequencer were used. Allele loss was scored if the area under an allelic peak was reduced to $<50 \%$ of its original value (relative to the other allele).

\section{Results}

Of the 20 families studied, 17 were consistent with linkage of PJS to D19S886. In these 17 families, probable recombinations with the disease locus were observed at D19S565 in three affected and one unaffected subjects. No obligate recombinants with the disease locus were observed at D19S878 or D19S886. There was a total of 49 affected subjects in the 17 families in which disease was apparently linked to 19p13.3. Based on haplotype sharing with affected subjects in the same family and assuming linkage to $19 \mathrm{p} 13.3$, there was evidence for non-penetrance in just one apparently unaffected subject (current age $\sim 40$ years).

Three families (G69, G199, and G842) were shown by haplotype inspection to be unlinked to chromosome 19p13.3 (fig 1). The number of people in these families is too small to assess formally whether their clinicopathological features differed significantly from the $19 \mathrm{p} 13.3$ linked pedigrees. There were, however, no striking features to distinguish the $19 \mathrm{p} 13.3$ unlinked families from the others. In particular, the PJS polyps from the three unlinked families all appeared to show typical features. No allele loss at D19S886 or D19S878 was observed in a total of 10 polyps from family 199 (subject 374) and family 842 (subjects 4858 and 2563).

Combined two point lod scores at D19S886, D19S878, and D19S565 are shown in table 1 . These scores illustrate the results from haplotype inspection. Overall maximum lod scores ( $\mathrm{Zmax}$, table 1 ) were 1.54 at $\theta=0.14$ for locus D19S886, 1.49 at $\theta=0.15$ for locus D19S878, and 0.00 at $\theta=0.50$ for locus D19S565. HOMOG analysis estimated the proportion of families linked to D19S886 as $88 \%$ (5\% confidence limits: $100 \%$ and $20 \%$ ) with $\mathrm{Zmax}$ of 1.36 at $\theta=0.19$.

\section{Discussion}

There is compelling evidence of a PeutzJeghers locus on chromosome 19p13.3, close to the D19S886 microsatellite marker. Combining the results of this study at D19S886 with the original analysis of Hemminki et al ${ }^{4}$ gives a maximum two point lod score of nearly 6 at $\theta \sim 0.05$ (even when the three families unlinked to $19 \mathrm{p} 13.3$ are included). Nevertheless, the existence of three families unlinked to D19S886 in this study provides evidence that there is a second, minor PJS locus (or even more than one additional PJS locus).

It is almost certain that each of the $19 p$ unlinked families has PJS rather than another hamartomatous disease such as juvenile polyposis, as the histology of polyps from these families has been checked by several independent pathologists. The failure to observe allele loss at D19S886 or D19S878 in polyps from two of the 19p unlinked families (even allowing for the fact that some cases will have small scale mutations and for problems of contaminating stroma) fails to provide any support for linkage of these families' disease to $19 \mathrm{p} 13.3$. Misdiagnosis of polyps or pigmentation in certain critical subjects from the families unlinked to 19 p13.3 does, however, remain a possibility, although all patients were under the care of specialist clinicians. For this explanation to be correct, a minimum of the following would have to have been misdiagnosed as affected: subject 4815 (family G842) with pigmentation only; subject 376 (family G199) with polyps and pigmentation; and subject 3986 (family G69) with polyps and pigmentation. In addition, non-penetrance of the disease allele would have to have occurred in three or four people.

If there is a second PJS locus, where might it be? The first good candidate sites for a PJS locus were the chromosomal breakpoints in a patient with a pericentric inversion of chromosome 6 and PJS. ${ }^{5}$ Haplotype inspection (details not shown) in the three families unlinked to 19 p13.3 shows that the disease is not linked to markers at either of the breakpoint sites, or to the site of the maximum lod score on chromosome 6 previously reported by Tomlinson et al. ${ }^{6}$ The only other good candidate region for a PJS 

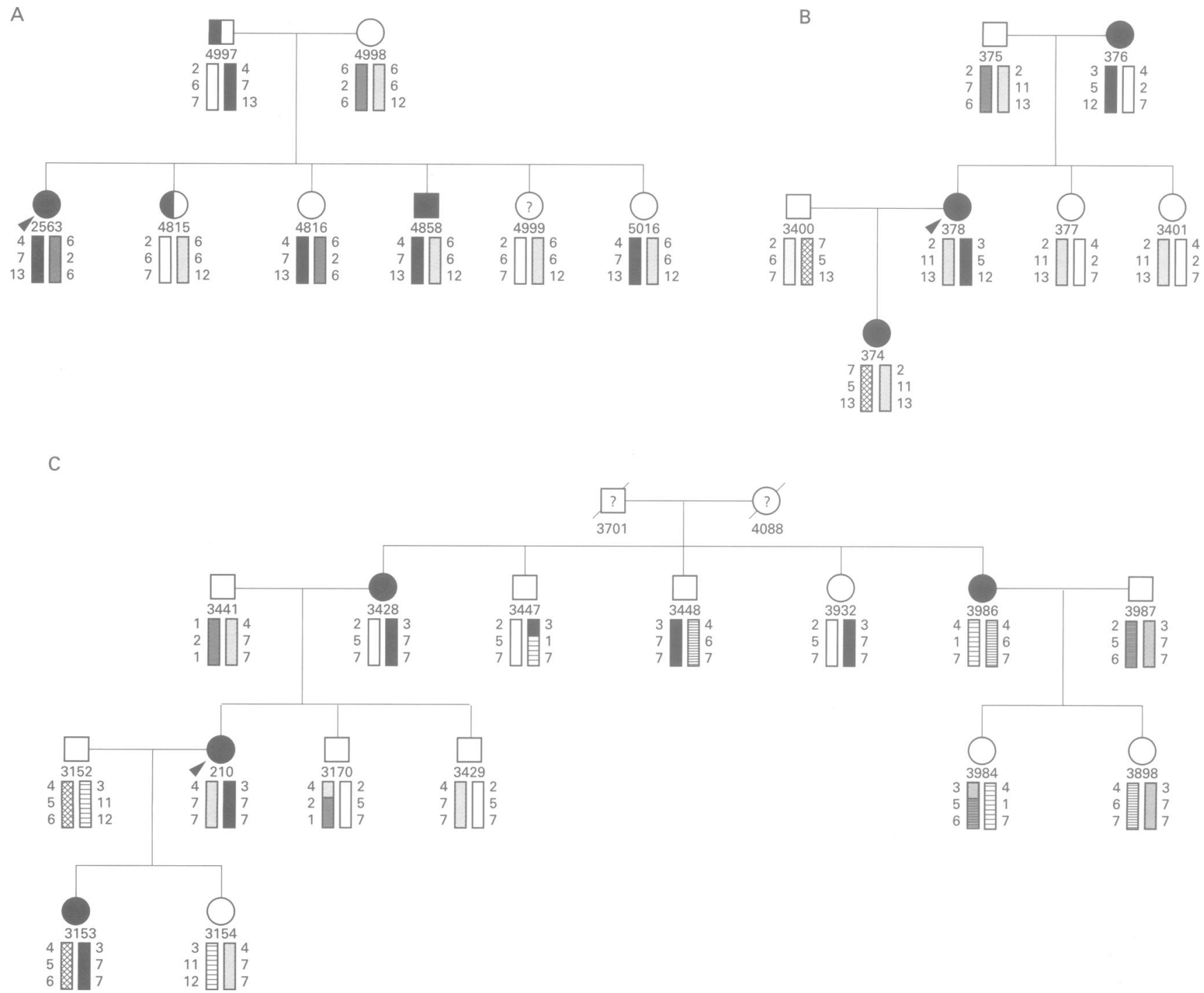

Figure 1 The three families unlinked to chromosome 19p13.3. Families $G 69$ (A), G199 (B), and G842 (C) are shown. Affected subjects (confirmed

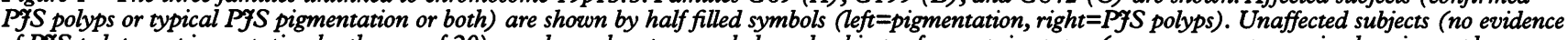
of PfS polyps or pigmentation by the age of 20) are shown by open symbols and subjects of uncertain status (young age, not examined, or incomplete records) by ?. Genotypes for D19S886, D19S878, and D19S565 are shown (in descending order along the haplotype bar). There is a failure of any $19 p 13.3$ haplotype to segregate consistently with the disease in these families.

gene, 1p32-p34, was proposed by Bali et al and Seldin et al using two families, but was subsequently excluded when extra pedigree members were genotyped (see OMIM 175200).

The evidence for genetic heterogeneity in PJS causes potential problems for positional cloning efforts, which rely on critical recombinants in families apparently linked to 19p13.3. If these families are actually linked to a second PJS locus, positional cloning efforts may be directed to the wrong region. The existence of genetic heterogeneity makes predictive testing using linkage analysis in PJS families a difficult task, until the major PJS gene is cloned. Finding the second PJS locus by linkage analysis might prove difficult if the great majority of families is linked to $19 \mathrm{p} 13.3$. Repeating CGH on the polyps of unlinked families is a possible strategy for mapping a second PJS gene. Further clues might emerge following identification of the first PJS locus, when a search for homologues or candidate ligand/receptor loci could be undertaken.
We thank the families themselves and the following clinicians: B Bachy, J F Colombel, J L Dabadie, P Eugene, P Hammel, P Martasek, M Mathieu, A Munck, and R Parc.

1 Spigelman AD, Arese P, Phillips RKS. Polyposis - the Peutz-Jeghers syndrome. Br 7 Surg 1995;82:1311-14.

$2 \mathrm{Li}$ J, Yen C, Liaw D, et al. PTEN, a putative protein tyrosine phosphatase gene mutated in human brain, breast, and prostate cancer. Science 1997;275:1943-7.

3 Liaw D, Marsh DJ, Li J, et al. Germline mutations of the PTEN gene in Cowden disease, an inherited breast and thyroid cancer syndrome. Nat Genet 1997;16:64-7.

4 Hemminki A, Tomlinson IPM, Markie D, et al. Localisation of a susceptibility locus for Peutz-Jeghers syndrome using comparative genomic hydridisation and targeted linkage comparative genomic hydridisatio

5 Markie D, Huson S, Maher E, Davies A, Tomlinson IPM, Bodmer WF. A pericentric inversion of chromosome six in a patient with Peutz-Jeghers syndrome and the use of FISH to localise the breakpoints on a genetic map. Hum Genet 1996;98:125-8

6 Tomlinson IPM, Olschwang S, Abelovitch D, et al. Testing candidate loci on chromosomes 1 and 6 for genetic linkage to Peutz-Jeghers disease. Ann Hum Genet 1996;60:377-84.

7 Bali D, Gourley IS, McGarrity TJ, et al. Peutz-Jeghers synBali D, Gourley IS, McGarrity TJ, et al. Peutz-Jeghers syn-
drome maps to chromosome 1p. Am $\mathcal{F}$ Hum Genet 1995;57: S1067.

8 Seldin MF, Bali D, Gourley IS, et al. Preliminary linkage of Peutz-Jeghers syndrome to chromosome 1p. Cytogenet Cell Genet 1996;172:151. 